\title{
Liver Cancer Pathologic Primary Tumor TNM Finding v7
}

National Cancer Institute

\section{Source}

National Cancer Institute. Liver Cancer Pathologic Primary Tumor TNM Finding V7. NCI

Thesaurus. Code 190153.

A pathologic finding about one or more characteristics of liver cancer, following the rules of the TNM AJCC V7 classification system as they pertain to staging of the primary tumor. 